\title{
Comparison of the effect of multiple short-duration with single long-duration exercise sessions on glucose homeostasis in type 2 diabetes mellitus
}

\author{
L. Eriksen • I. Dahl-Petersen • S. B. Haugaard • F. Dela
}

Received: 15 April 2007 / Accepted: 27 June 2007 / Published online: 1 September 2007

(C) Springer-Verlag 2007

\begin{abstract}
Aims/hypothesis We evaluated and compared the effects on glycaemic control of two different exercise protocols in elderly men with type 2 diabetes mellitus.

Methods Eighteen patients with type 2 diabetes mellitus carried out home-based bicycle training for 5 weeks. Patients were randomly assigned to one of two training programmes at $60 \%$ of maximal oxygen uptake: three 10 min sessions per day $(3 \times 10)$ or one $30 \mathrm{~min}$ session per day $(1 \times 30)$. Plasma insulin, C-peptide and glucose concentrations were measured during a $3 \mathrm{~h}$ oral glucose tolerance test (OGTT). Insulin

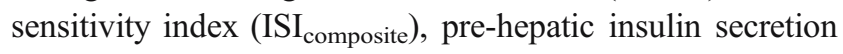
rates (ISR) and change in insulin secretion per unit change in glucose concentrations $\left(\mathrm{B}_{\text {total }}\right)$ were calculated.

Results Cardiorespiratory fitness increased in response to training in both groups. In group $3 \times 10(n=9)$ fasting plasma glucose $(p=0.01), 120 \mathrm{~min}$ glucose OGTT $(p=0.04)$ and plasma glucose concentration areas under the curve at $120 \mathrm{~min}(p<0.04)$ and $180 \mathrm{~min}(p=0.07)$ decreased. These parameters remained unchanged in group $1 \times 30(n=9)$. No

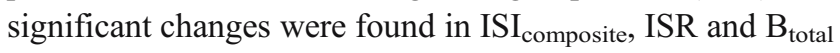
in either of the exercise groups. In a matched time-control group $(n=10)$, glycaemic control did not change.
\end{abstract}

L. Eriksen • I. Dahl-Petersen • F. Dela $(\bowtie)$

Department of Biomedical Sciences,

The Copenhagen Muscle Research Centre,

Faculty of Health Sciences, University of Copenhagen,

Blegdamsvej 3,

2200 Copenhagen, Denmark

e-mail: fdela@mfi.ku.dk

S. B. Haugaard

Clinical Research Unit and Department of Endocrinology,

Hvidovre Hospital, University of Copenhagen,

Hvidovre, Denmark
Conclusions/interpretation Moderate to high-intensity training performed at $3 \times 10 \mathrm{~min} /$ day is preferable to $1 \times 30 \mathrm{~min} /$ day with regard to effects on glycaemic control. This is in spite of the fact that cardiorespiratory fitness increased similarly in both exercise groups. A possible explanation is that the energy expenditure associated with multiple short daily sessions may be greater than that in a single daily session.

Keywords Cardiovascular fitness · Energy expenditure · Exercise · Glycaemic control · Insulin resistance · Physical training · Skeletal muscle · Type 2 diabetes mellitus

$\begin{array}{ll}\begin{array}{l}\text { Abbreviations } \\ \text { ANCOVA }\end{array} & \begin{array}{l}\text { analysis of covariance } \\ \text { change in insulin secretion per unit change in } \\ \text { glucose concentrations }\end{array} \\ \mathrm{B}_{\text {total }} & \begin{array}{l}\text { excess post-exercise oxygen consumption } \\ \text { EPOC }\end{array} \\ \text { ISI } & \begin{array}{l}\text { insulin sensitivity index } \\ \text { ISR }\end{array} \\ \dot{V} O_{2 \max } & \text { maximal oxygen uptake }\end{array}$

\section{Introduction}

At the time of diagnosis approximately one-half of patients with type 2 diabetes mellitus have symptoms of long-term complications. A positive association has been found between the glycaemic level and the risk of complications [1, 2]. Furthermore, fasting blood glucose has found to be positively associated with mortality $[3,4]$. To prevent and delay these severe long-term complications, good glycaemic control is a major goal in the treatment of type 2 diabetes mellitus.

Exercise is considered to be a substantial part of the treatment of type 2 diabetes mellitus [5]. In a meta-analysis 
of Boulé et al. [6], exercise training was found to reduce $\mathrm{HbA}_{1 \mathrm{c}}$ by 0.66 percentage points. This is close to the effect of intense glucose-lowering pharmacological treatment found in the United Kingdom Prospective Diabetes Study [1].

The National Board of Health and the Danish Diabetes Association recommends that all adults, including type 2 diabetic patients, should be physically active with at least $30 \mathrm{~min}$ of moderate intensity every day. The current recommendation is that the physical activity may be accumulated during the day, for instance in three bouts of $10 \mathrm{~min}$. However, in patients with type 2 diabetes this is not based on solid experimental evidence. In healthy men, evidence has been found for improvements in physical fitness after long-term aerobic exercise of moderate intensity performed both in single exercise sessions, as well as in multiple shortterm sessions [7]; in patients with type 2 diabetes only the acute effect on glucose control of dividing the exercise session into smaller bouts has been studied [8]. Evidence of long-term effects on glycaemic control based on the present recommendations of physical activity has to our knowledge not been documented for type 2 diabetic patients.

The aim of the present study was to investigate and compare the effect on glycaemic control of two different exercise interventions: a single exercise session of $30 \mathrm{~min} /$ day (group $1 \times 30)$ or three short $(10 \mathrm{~min})$ exercise sessions per day (group $3 \times 10$ ). Data from such a study may support future exercise recommendations in the treatment of type 2 diabetes mellitus.

\section{Methods}

Patients We recruited patients through advertisements in newspapers. The inclusion criteria were: men diagnosed with type 2 diabetes mellitus, aged 50 to 70 years, BMI $>27 \mathrm{~kg} / \mathrm{m}^{2}$, treated with diet and/or oral glucose-lowering medication and not participating in any vigorous physical activity. Patients were initially screened through a telephone interview and were only included if they had no history of cardiovascular disease or other chronic conditions that would preclude the ability to engage in exercise on an ergometer bike.

Of the 18 patients that completed the intervention, six had diet-controlled diabetes and 12 were being treated with oral hypoglycaemic drugs. During the study period medication levels were not modified.

Written informed consent was obtained from all patients. The study was approved by the local ethics committee in accordance with the guidelines published in the declaration of Helsinki.

Study design Patients were randomised to one of two exercise groups: $3 \times 10 \mathrm{~min} /$ day $(n=10)$ or $1 \times 30 \mathrm{~min} /$ day $(n=13)$. A time-control group was also included $(n=10)$. In the intervention groups, the patients were tested before initialising the training and in the fifth week of training (see below). Blood samples were collected at least $16 \mathrm{~h}$ after the last exercise bout. In one patient in the $1 \times 30$ group, blood was sampled later at $72 \mathrm{~h}$ after the last exercise bout. The result from this particular patient was in line with those from the other patients. Patients in the time-control group were tested twice, with 4 to 5 weeks in-between.

Patient inclusion The patient inclusion procedure is illustrated in Fig. 1. A total of 23 men volunteered to participate after receiving written information about the study. Of these, 19 completed the intervention, one of whom was subsequently excluded for not adhering to the exercise protocol.

All patients were tested at Department of Biomedical Sciences, Faculty of Health Sciences, University of Copenhagen before initialising the training and in the fifth week of training.

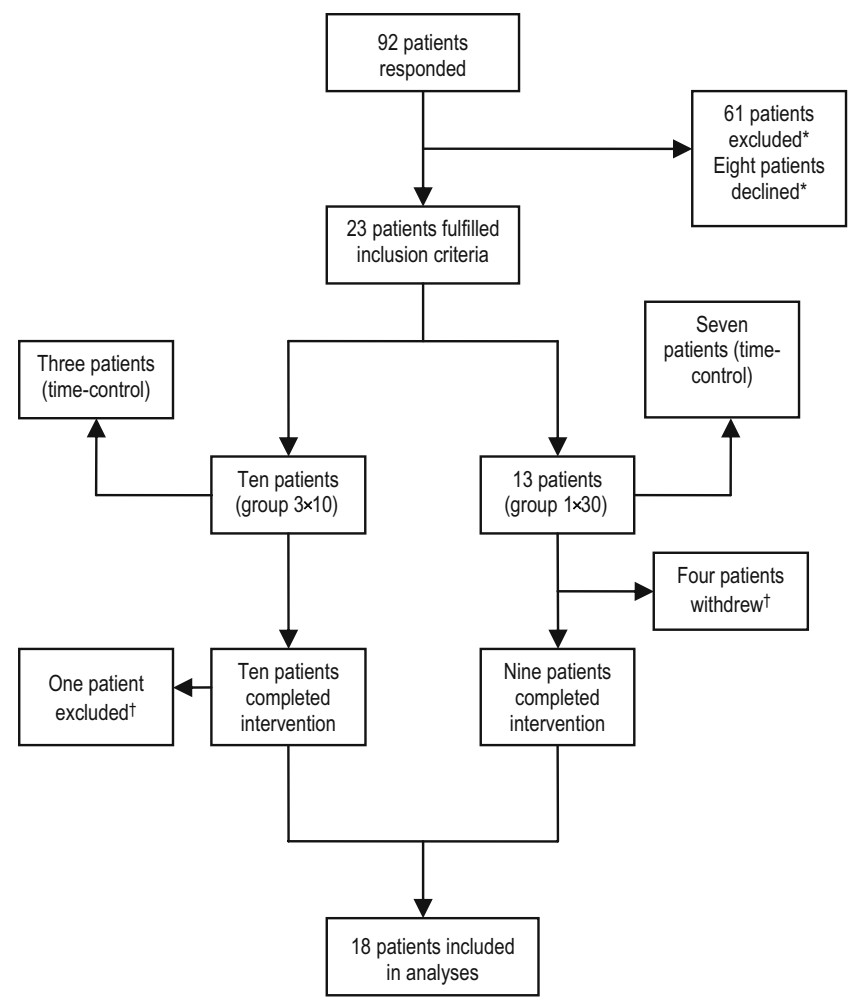

Fig. 1 Study design. *The majority of those excluded did not fulfil the inclusion criteria mainly with regard to BMI, cardiovascular disease and level of physical activity. Of those who declined, five withdrew for specific reasons and three for unknown reasons. ${ }^{\top}$ Two patients withdrew after the first test day, one due to changes in job situation, the other for unknown reasons. Two patients withdrew during the first week of the exercise period, one due to additional disease and one who found the exercise too strenuous and timeconsuming. Finally, one patient was excluded from the analysis for not adhering to the required level of intensity 
Baseline characteristics The patients were overweight or obese (BMI $27-41 \mathrm{~kg} / \mathrm{m}^{2}$ ), had abdominal adiposity (waist circumference $>94 \mathrm{~cm}$ ) and were normo- or hypertensive (120-170/70-100 $\mathrm{mmHg}$ ). The time since the diagnosis of type 2 diabetes mellitus ranged from 1 to 14 years, and $\mathrm{HbA}_{1 \mathrm{c}}$ and fasting capillary glucose concentration indicated both good and poor glycaemic control at baseline $\left(\mathrm{HbA}_{1 \mathrm{c}} 5.9\right.$ $10.5 \%$, capillary glucose $7.0-14.6 \mathrm{mmol} / \mathrm{l}$ ) (Table 1 ).

At baseline there were no significant differences between the groups with the exception of BMI, which was slightly higher in group $3 \times 10$ than in group $1 \times 30(p=0.03)$ (Table 1$)$.

Experimental day On the experimental days the patients arrived at the laboratory in the morning after a $9 \mathrm{~h}$ fast and abstinence from their usual glucose-lowering medical treatment. The patients were instructed to avoid strenuous physical activity on the morning of the experiment. Body weight and height were measured. The fat mass of each patient was determined by dual-energy X-ray absorptiometry scan (LUNAR DPX-IQ; Lunar Corporation, Madison, WI, USA). The waist circumference was measured in an upright posture at the widest part of the abdomen. Blood pressure was measured, and resting and exercise ECGs were obtained. A capillary blood sample was taken to measure fasting capillary blood glucose and venous blood samples were collected for biochemical analysis (Table 1). The patients then underwent a $3 \mathrm{~h}$ oral glucose tolerance test (OGTT), ingesting a solution of $75 \mathrm{~g}$ glucose dissolved in $300 \mathrm{ml}$ water. During the OGTT the hand of the patient was placed in a heating pad in order to obtain arterialised blood samples. Blood was sampled before and during the OGTT for measurement of plasma glucose (ABL, series 700; Radiometer, Copenhagen, Denmark), insulin and C-peptide concentrations.

Glucose tolerance Glucose tolerance was measured by calculating the area under the curve (AUC) for plasma glucose concentrations during the OGTT by means of the trapezoidal rule. Areas were calculated for 2 and $3 \mathrm{~h}$. The AUC was also calculated for plasma insulin and C-peptide concentrations.

Insulin sensitivity To estimate whole-body insulin sensitiv-

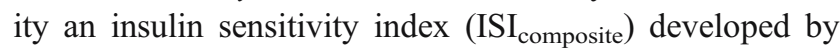
Matsuda and DeFronzo [9] was used:

$$
\text { ISI }_{\text {composite }}=\frac{10,000}{\sqrt{\begin{array}{r}
\text { FPG } \times \text { FPI } \times \text { MeanGluOGTT }_{0-120 \text { min }} \\
\times \text { MeanInsOGTT }_{0-120 \text { min }}
\end{array}}}
$$

The value 10,000 represents a constant, which allows values ranging from 0 to 12 to be obtained. FPG and FPI are the fasting plasma glucose $(\mathrm{mg} / \mathrm{dl})$ and fasting plasma insulin $(\mu \mathrm{U} / \mathrm{ml})$, respectively. MeanGluOGTT ${ }_{0-120} \min$ and MeanInsOGTT $_{0-120} \min$ are the average of the plasma

Table 1 Baseline characteristics

\begin{tabular}{|c|c|c|c|}
\hline & Group $1 \times 30(n=9)$ & Group $3 \times 10(n=9)$ & Time-control $(n=10)$ \\
\hline Age (years) & $59 \pm 8$ & $60 \pm 4$ & $61 \pm 7$ \\
\hline Time since diagnosis (years) & $7(1-14)$ & $6(1-11)$ & $7(1-12)$ \\
\hline Weight $(\mathrm{kg})$ & $95(81-106)$ & $106(69-131)$ & $99(86-107)$ \\
\hline BMI $\left(\mathrm{kg} / \mathrm{m}^{2}\right)^{\mathrm{a}}$ & $30(27-37)$ & $35(29-41)$ & $31(28-37)$ \\
\hline Total fat $(\%)$ & $32(25-38)$ & $37(29-45)$ & $33(24-45)$ \\
\hline Waist circumference $(\mathrm{cm})$ & $110.4 \pm 9.6$ & $121.9 \pm 14.3$ & $111.6 \pm 9.2$ \\
\hline $\mathrm{HbA}_{1 \mathrm{c}}(\%)$ & $7.5(5.9-10.5)$ & $7.6(5.9-10.0)$ & $7.5(6.1-10.5)$ \\
\hline Triacylglycerol (mmol/l) & $1.7(0.89-2.69)$ & $1.3(0.86-2.8)$ & $1.6(0.9-2.7)$ \\
\hline LDL-cholesterol (mmol/l) & $2.7(1.9-3.7)$ & $2.5(0.9-4.1)$ & $2.5(0.9-3.7)$ \\
\hline HDL-cholesterol (mmol/1) & $1.3(0.9-1.8)$ & $1.2(0.9-1.6)$ & $1.2(0.9-1.8)$ \\
\hline VLDL-cholesterol (mmol/1) & $0.8(0.4-1.2)$ & $0.6(0.4-0.9)$ & $0.7(0.4-1.2)$ \\
\hline Systolic blood pressure (mmHg) & $135(120-145)$ & $143(125-170)$ & $137(123-150)$ \\
\hline Diastolic blood pressure (mmHg) & $86(70-98)$ & $89(70-100)$ & $87(75-98)$ \\
\hline$\dot{V} O_{2 \max }(\mathrm{ml} / \mathrm{min})$ & $2,227 \pm 477$ & $2,225 \pm 438$ & $2,073 \pm 415$ \\
\hline$\dot{V} O_{2 \max }\left(\mathrm{ml} \mathrm{min} \operatorname{mog}^{-1} \mathrm{~kg}^{-1}\right)$ & $23.8 \pm 6.6$ & $21.4 \pm 5.2$ & $22.5 \pm 5.7$ \\
\hline Fasting plasma C-peptide (pmol/l) & $1,006(545-1,648)$ & $1,154(660-1,572)$ & $1,054(631-1,648)$ \\
\hline Fasting plasma insulin (pmol/1) & $63.6(29.7-110.4)$ & $75.2(34.2-112.7)$ & $70.9(29.7-112.7)$ \\
\hline Fasting capillary glucose (mmol/l) & $10.5(7.0-14.6)$ & $10.9(8.5-14.2)$ & $10.7(7.0-14.6)$ \\
\hline $\mathrm{B}_{\text {total }}\left(\mathrm{pmol} \mathrm{kg}{ }^{-1} \min ^{-1}[\mathrm{mmol} / 1]^{-1}\right)$ & $0.033(0.008-0.067)$ & $0.020(0.01-0.034)$ & $0.024(0.005-0.067)$ \\
\hline ISI $_{\text {composite }}$ & $4.0(1.6-7.7)$ & $3.3(1.6-5.8)$ & $3.8(1.6-7.7)$ \\
\hline $\operatorname{AUC} \mathrm{OGTT}_{0-180 \min } \mathrm{ISR}(\mathrm{pmol} / \mathrm{l})$ & $1,129(528-2,043)$ & $1,002(560-1,457)$ & $1,048(503-2,043)$ \\
\hline
\end{tabular}

Values are means $\pm \mathrm{SD}$ or range (minimum-maximum)

$V L D L$ very-low-density lipoprotein

${ }^{\mathrm{a}} p=0.03$ for difference between group $3 \times 10$ vs group $1 \times 30$ 
glucose and plasma insulin concentrations measured at -10 , 0, 30, 60, 90 and 120 min during the OGTT.

Insulin secretion rates and beta cell responsiveness The pre-hepatic insulin secretion rates (ISR) were calculated by the computer program ISEC (insulin secretion) by deconvolution of plasma C-peptide concentrations [10]. From the ISR the AUC during the OGTT (AUC OGTT ISR O-180 min $_{\text {) }}$ was calculated. Thus, AUC OGTT ISR $0-180$ min is an expression of the total amount of pre-hepatic insulin secreted during the OGTT [11]. The individual relationships between plasma glucose concentrations and ISRs during the OGTT were evaluated by cross-correlation analysis. The change in insulin secretion per unit change in glucose concentrations $\left(\mathrm{B}_{\text {total }}\right)$ is used as a measure of beta cell responsiveness [11].

Cardiorespiratory fitness Cardiorespiratory fitness was determined by a sub-maximal exercise test, in which patients worked below maximal effort, followed by a maximal exercise test, in which patients worked until exhaustion. The exercise tests were performed on an ergometer bike. The sub-maximal exercise test was 8 min duration with incrementally increasing workloads $(40,60,75$ and $90 \mathrm{~W})$. Before and at the end of each workload, capillary blood samples were obtained and analysed for lactate concentration (ABL 700; Radiometer). In the maximal exercise test, the baseline workload and the stepwise increment in workload were individually determined for each patient, depending on his level of exertion during the sub-maximal exercise test. The intention was for all patients to reach a respiratory exchange ratio greater than $1.0 \mathrm{and} /$ or a heart rate at the age-predicted maximum (220-age [years]). A capillary blood sample was taken at maximum exhaustion level and analysed for lactate concentration. Oxygen consumption and carbon dioxide production were measured using a Jaeger OxyconPro (Intramedic A/S, Lyngby, Denmark).

Intervention The exercise intervention was home-based and consisted of $30 \mathrm{~min}$ of training 6 days/week for 4 to 5 weeks at a moderate to high intensity on an ergometer bike (Monark 828E or 818E; Monark Exercise AB, Varberg, Sweden). The appropriate workload was prescribed on an individual basis corresponding to 60 to $65 \%$ of maximal oxygen uptake $\dot{V} O_{2 \max }$ achieved during maximal exercise test. Patients were instructed to adjust the intensity by means of perception of exertion (corresponding to level 13-14 [somewhat hard] on the Borg Scale) combined with heart rate monitoring. Workloads were increased as fitness increased, thus maintaining a constant relative workload.

The patients wore a heart rate monitor (POLAR S610i; Polar Electro Oy, Kempele, Finland), allowing control of compliance in terms of exercise time and intensity. During the exercise intervention we contacted the patients by telephone (one to five calls) or by home visits (one to two visits) to encourage and supervise according to individual needs. The patients who performed exercise in multiple sessions per day were requested to spread the three sessions throughout the day (morning, afternoon, evening). This requested spreading of exercise sessions was also controlled by means of the heart rate monitors. Beyond the exercise sessions the patients were requested to maintain their usual daily level of activity and sustain normal eating habits.

Time-control group The patients who were enrolled for the time-control group went through the test day twice with 4 to 5 weeks in-between. Subsequently, they initiated the exercise intervention. During the time-control period the patients were requested to maintain their usual diet and activity habits.

Statistical tests Calculations were performed by SPSS version 13. Two sided $p$ values less than 0.05 were defined as statistically significant. If parameters deviated from the normal distribution or if variance homogeneity was not found, data were log-transformed. Baseline values are presented as means and SD or ranges. An unpaired $t$ test was used to compare baseline values between the two exercise groups and between exercise groups and the timecontrol group. Group differences are presented as percentage change for log-transformed data and as means if not log-transformed. Both are presented with $95 \%$ CIs. The effects of exercise were analysed by comparing baseline and after training values in each of the two groups by a paired $t$ test. An analysis of covariance (ANCOVA) was used to compare effects between the two exercise groups. In an ANCOVA each parameter is adjusted by its baseline value. To determine the effect in cardiorespiratory fitness, we used a three-way ANOVA with repeated measurements for lactate and heart rate values during sub-maximal exercise tests. Finally, a paired $t$ test was used for comparison of the two test days in the time-control group.

\section{Results}

Cardiorespiratory fitness and compliance In both exercise groups, submaximal heart rate and plasma lactate concentrations decreased to a similar degree after training (Table 2, Fig. 2). $\dot{V} O_{2 \max }$ increased by $9 \%(p=0.05)$ and $15 \%(p=0.07)$ in group $3 \times 10$ and group $1 \times 30$, respectively.

The patients carried out $98 \%$ (range $90-100 \%$ ) of the expected training sessions in group $3 \times 10$ and 98 (range 93-100) of the expected training sessions in group $1 \times 30$. The heart rate during the training sessions corresponded to an average of $68 \%$ (range 55-81\%) and $68 \%$ (range 
Table 2 Comparison of baseline and after training values in the two exercise groups

\begin{tabular}{|c|c|c|c|c|c|c|}
\hline & \multicolumn{3}{|l|}{ Group $1 \times 30$} & \multicolumn{3}{|l|}{ Group $3 \times 10$} \\
\hline & Change (\%) & $95 \% \mathrm{CI}$ & $p$ value & Change $(\%)$ & $95 \% \mathrm{CI}$ & $p$ value \\
\hline Fasting capillary glucose & 3.3 & $-5.6,11.0$ & 0.42 & -9.6 & $-19.4,-2.9$ & 0.01 \\
\hline 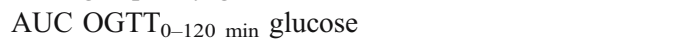 & -1.6 & $-7.8,3.5$ & 0.44 & -7.5 & $-16.2,-0.4$ & 0.04 \\
\hline AUC OGTT $_{0-180 \text { min }}$ glucose & -1.5 & $-6.8,3.1$ & 0.44 & -6.1 & $-13.3,0.6$ & 0.07 \\
\hline OGTT $_{120 \text { min }}$ glucose & -2.4 & $-7.7,3.7$ & 0.47 & -3.1 & $-16.3,-0.6$ & 0.04 \\
\hline Fasting plasma insulin & 7.1 & $-14.2,24.5$ & 0.43 & -3.8 & $-25.4,14.1$ & 0.66 \\
\hline AUC OGTT $_{0-180 \text { min }}$ insulin & -8.2 & $-18.4,12.0$ & 0.76 & -3.4 & $-18.0,17.0$ & 0.89 \\
\hline Fasting plasma C-peptide & 4.6 & $-8.0,15.7$ & 0.41 & 0.9 & $-10.6,13.7$ & 0.68 \\
\hline AUC OGTT $_{0-180 \text { min }}$ C-peptide & 0.7 & $-6.8,7.8$ & 0.81 & 1.9 & $-10.5,14.3$ & 0.64 \\
\hline ISI $_{\text {composite }}$ & -3.2 & $-20.6,13.5$ & 0.78 & 9.4 & $-5.3,25.7$ & 0.14 \\
\hline $\mathrm{B}_{\text {total }}$ & -11.0 & $-46.2,13.1$ & 0.29 & -1.6 & $-33.4,40.1$ & 0.86 \\
\hline AUC OGTT $_{0-180 \min }$ ISR & 0.3 & $-5.9,7.2$ & 0.77 & 4.9 & $-8.0,16.0$ & 0.40 \\
\hline Weight & 0.1 & $-0.6,0.8$ & 0.79 & -0.4 & $-1.0,0.3$ & 0.21 \\
\hline BMI & 0.1 & $-0.6,0.8$ & 0.72 & -0.4 & $-1.0,0.3$ & 0.21 \\
\hline Fat mass & -2.7 & $-5.9,0.4$ & 0.08 & -1.2 & $-5.5,2.9$ & 0.52 \\
\hline $\mathrm{HbA}_{1 \mathrm{c}}$ & -0.8 & $-2.7,1.3$ & 0.41 & -2.0 & $-6.4,2.6$ & 0.35 \\
\hline Triacylglycerol & -8.5 & $-32.1,10.9$ & 0.37 & -7.4 & $-28.1,9.2$ & 0.35 \\
\hline LDL-cholesterol & 8.6 & $-11.4,25.0$ & 0.32 & -8.9 & $-21.7,2.5$ & 0.11 \\
\hline HDL-cholesterol & -2.0 & $-8.2,3.9$ & 0.47 & -4.1 & $-9.2,0.9$ & 0.10 \\
\hline VLDL-cholesterol & -6.0 & $-26.6,11.3$ & 0.47 & -5.9 & $-29.7,13.5$ & 0.53 \\
\hline Systolic BP & -7.3 & $-8.6,3.6$ & 0.41 & -2.5 & $-7.4,2.2$ & 0.26 \\
\hline Diastolic BP & -3.0 & $-11.1,4.5$ & 0.40 & -5.1 & $-13.6,2.8$ & 0.18 \\
\hline Waist circumference $(\mathrm{cm})^{\mathrm{a}}$ & -0.9 & $-2.7,1.0$ & 0.30 & 0.42 & $-0.6,1.5$ & 0.38 \\
\hline$\dot{V} O_{2 \max }(\mathrm{ml} / \mathrm{min})^{\mathrm{a}}$ & 329 & $-41,700$ & 0.07 & 177 & $-4,358$ & 0.05 \\
\hline$\dot{V} O_{2 \max }\left(\mathrm{ml} \mathrm{min}^{-1} \mathrm{~kg}^{-1}\right)^{\mathrm{a}}$ & 3.3 & $-0.6,7.2$ & 0.09 & 1.8 & $0.1,3.7$ & 0.04 \\
\hline Heart rate at sub-maximal work rates (beats per min) ${ }^{a, b}$ & -4.8 & $-6.8,-2.8$ & $<0.01$ & -6.9 & $-8.9,-5.0$ & $<0.01$ \\
\hline Lactate at sub-maximal work rates $(\mathrm{mmol} / \mathrm{l})^{\mathrm{a}}$ & -0.48 & $-0.68,-0.27$ & $<0.01$ & -0.43 & $-0.67,-0.20$ & $<0.01$ \\
\hline
\end{tabular}

Values are given as \% change $(95 \% \mathrm{CI})(\log$ transformed data)

$B P$ blood pressure, $V L D L$ very-low-density lipoprotein

${ }^{\text {a }}$ Mean difference (means [95\% CI]) between values measured at baseline and after training

${ }^{\mathrm{b}}$ Analysed by a three-way ANOVA with repeated measurements

$59-80 \%)$ of $\dot{V} O_{2 \max }$ in the first week of training in groups $3 \times 10$ and $1 \times 30$ respectively. The corresponding values in the fifth week of training were $68 \%$ (range 56-87\%) and $68 \%$ (range $57-83 \%$ ) of $\dot{V} O_{2 \max }$ in groups $3 \times 10$ and $1 \times 30$ respectively.

Glycaemic control In group $3 \times 10$ fasting capillary plasma glucose decreased significantly by $1.0 \mathrm{mmol} / 1$ in response to the training, whereas no change was seen in group $1 \times 30$ (Table 2, Fig. 3).

Glucose tolerance improved in group $3 \times 10$, with a statistically significant $7.5 \%$ decrease in $\mathrm{AUC} \mathrm{OGTT}_{0-120 \mathrm{~min}}$ glucose (Table 2). The AUC OGTT 180 min glucose decreased by $6 \%$ and was of borderline significance $(p=0.07)$. Plasma glucose concentrations at $t=120 \mathrm{~min}$ decreased by $0.5 \mathrm{mmol} / 1$ after training in group $3 \times 10(p=0.04)$. Group $1 \times 30$ showed no significant changes in glucose tolerance after training (Table 2, Fig. 4). No changes were found in fasting plasma insulin, fasting C-peptide concentrations, AUC OGTT $_{180 \text { min }}$ insulin and C-peptide in any of the exercise groups (Table 2, Fig. 4). No changes of these parameters were seen in the time-control group (data not shown).

None of the calculated indices of insulin sensitivity or

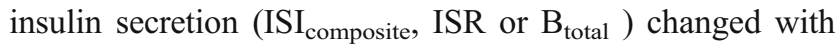
the exercise intervention in any of the groups $(3 \times 10,1 \times 30$ or time control group) (Table 2).

$H b A_{l c}$, lipids, anthropometric measures and blood pressure Despite a significant effect of training on glycaemic control in group $3 \times 10, \mathrm{HbA}_{1 \mathrm{c}}$ did not change in any of the two groups after the training period (Table 2), which may be explained by the relative short duration of the intervention (less than 3 months). No statistically significant changes in weight, total fat mass, waist circumference, BMI, blood pressure and lipids were observed in either of the groups. A decrease, albeit somewhat variable and not statistically significant, in systolic/diastolic blood pressure was seen in group $3 \times 10 \quad(-4$ [range -11.0 to 3.0$] /-4.4$ [range -10.8 to $1.9 \mathrm{mmHg}$ ). No significant changes were found in these parameters after pooling data from the intervention groups 


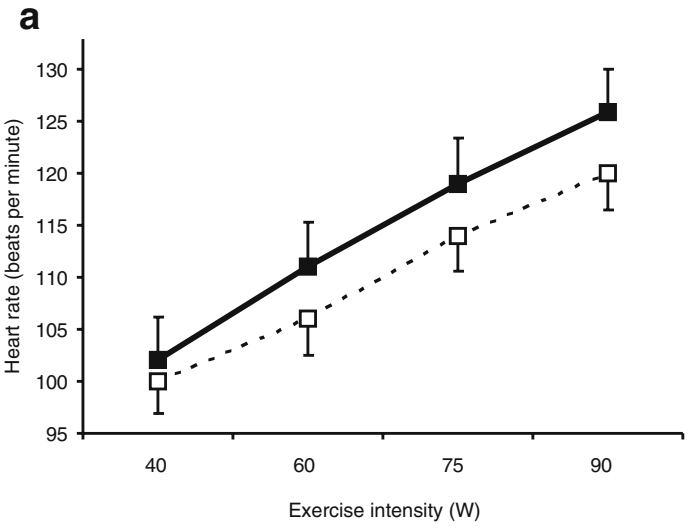

b

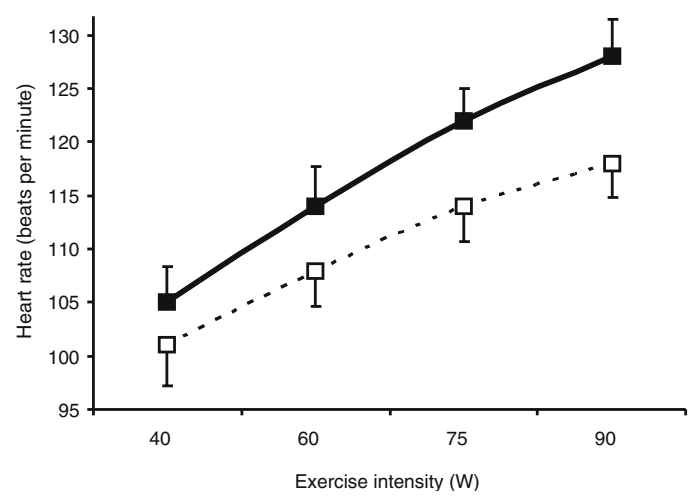

Fig. 2 Heart rate during sub-maximal exercise tests in group $1 \times 30$ (a) and group $3 \times 10$ (b). Closed squares and complete line, baseline; open squares and dotted line, after training. Error bar, SE

(data not shown). The time-control group did not experience any changes in the above parameters at the end of the time-control period (data not shown).

Comparing the two exercise groups adjusted for differences in baseline values for each of the parameters (ANCOVA), we found that fasting capillary plasma glucose differed between the two exercise groups after training (13.8\% [range 2.3-26.8\%], $p=0.02$ ). No significant differences between the two exercise groups were found in the remainder of the parameters.

\section{Discussion}

After 4 to 5 weeks of aerobic training performed at moderate to high intensity work rates, both exercise groups improved their cardiorespiratory fitness independently of group assignment. Nonetheless, glycaemic control, in terms of fasting glucose concentrations and glucose tolerance, only improved in the exercise group performing three short $10 \mathrm{~min}$ exercise sessions per day (group $3 \times 10$ ). In the exercise group performing one single daily exercise session of $30 \mathrm{~min}$ (group $1 \times 30$ ) glycaemic control did not change.
Both intervention groups improved their cardiorespiratory fitness, carried out the same accumulated amount of exercise and had an equally high compliance with training. It may therefore seem puzzling that glycaemic control should have improved only in the $3 \times 10$ group. A likely explanation is the possibility that total energy expenditure during training performed as multiple sessions is higher than that during one single session per day. Thus, due to the performance of three exercise bouts per day instead of one, group $3 \times 10$ probably had a higher total excess post-exercise oxygen consumption (EPOC) and thereby higher total energy expenditure. Following each of the exercise bouts, slightly elevated body temperature directly stimulates metabolism to increase recovery oxygen consumption. Moreover, restoration of pulmonary ventilation, as well as circulation and redistribution of calcium, potassium and sodium ions within muscle and other compartments also require additional energy. The notion that total EPOC for three separate 10 min exercise bouts is larger than EPOC for one 30 min exercise bout is supported by experimental evidence [12], where it has been shown that a tripling of treadmill walking time from $20 \mathrm{~min}$ to $60 \mathrm{~min}$, only doubled EPOC. However, in the present study, the difference in total energy expenditure between the two exercise interventions was probably so small that it made no difference to the cardiovascular fitness outcome. It is well known that even very small increases in daily energy expenditure can improve glucose homeostasis without
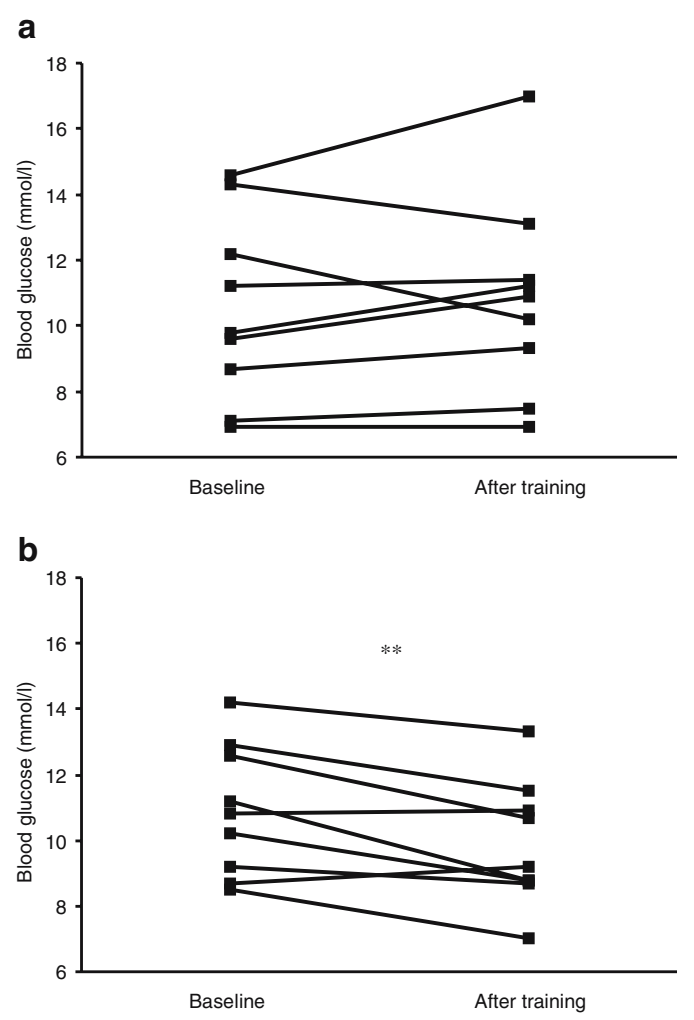

Fig. 3 Fasting capillary glucose at baseline and after training for each patient in group $1 \times 30(\mathbf{a})$ and group $3 \times 10(\mathbf{b}) ;{ }^{* *} p=0.01$ 
Fig. 4 Glucose tolerance during $3 \mathrm{~h}$ OGTT in group $1 \times 30$ (a) and in group $3 \times 10$ (b). Insulin concentration during $3 \mathrm{~h}$ OGTT in group $1 \times 30$ (c) and in group $3 \times 10$ (d). C-peptide concentration during $3 \mathrm{~h}$ OGTT in group $1 \times 30(\mathbf{e})$ and in group $3 \times 10(\mathbf{f})$ $* * p=0.01$ fasting glucose; $\dagger p=0.04$ AUC OGTT ${ }_{0-120 \text { min }}$ glucose and $\mathrm{OGTT}_{120 \mathrm{~min}}$ glucose; $₫ p=0.07$ AUC OGTT $_{0-180}$ min glucose. Closed squares and complete line, baseline; open squares and dotted line, after training. Error bars, SE a

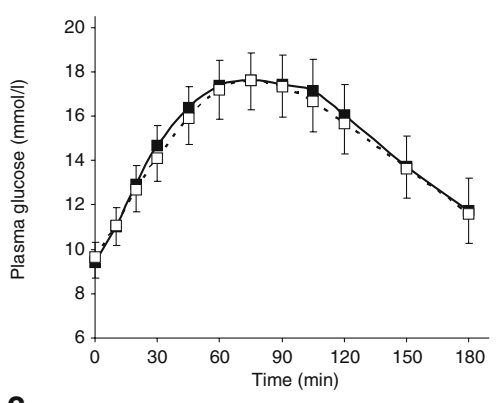

C

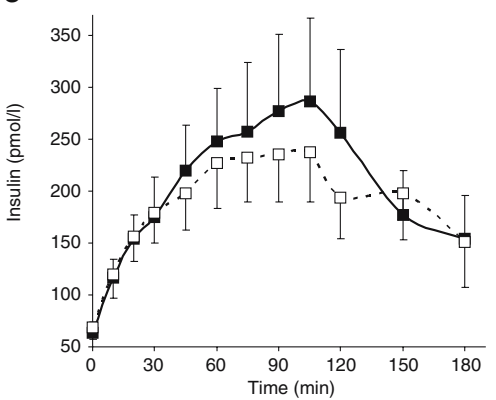

e

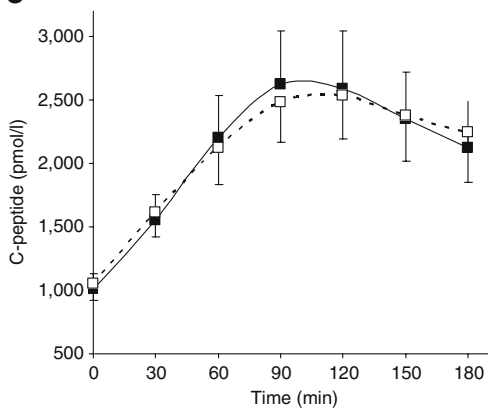

b

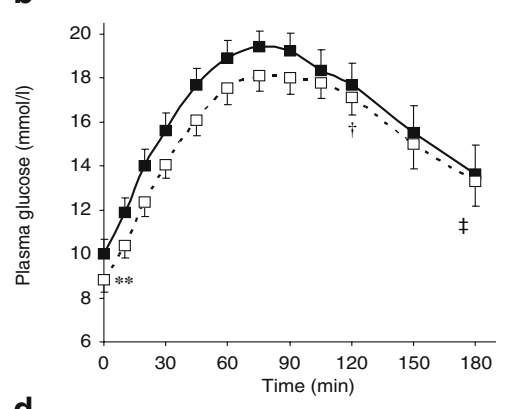

d

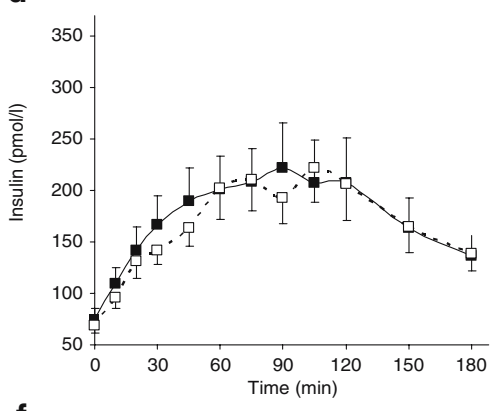

f

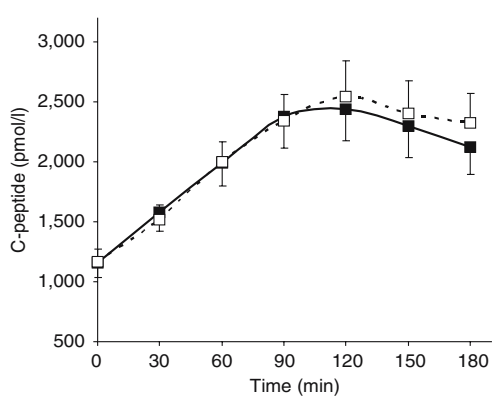

affecting cardiorespiratory fitness [13]. Altogether, the present findings are in accordance with the general belief that it is the total amount of energy spent in the exercise programme that determines the metabolic outcome $[14,15]$.

None of the calculated parameters, i.e. insulin sensitivity (ISI composite $), \mathrm{B}_{\text {total }}, \mathrm{AUC} \mathrm{OGTT}_{0-180}$ min C-peptide, AUC $\mathrm{OGTT}_{0-180}$ min insulin and AUC OGTT $0-180$ min ISR, changed in response to training in any of the exercise groups. Thus, it is impossible to deduce a clear mechanism to explain the improvement in glucose tolerance in group $3 \times 10$ vs group $1 \times 30$. A similar discrepancy between improvements in glucose tolerance and changes in measures of insulin sensitivity, insulin secretion and metabolic clearance rate of insulin has been reported previously [16]. In that study the exercise modality and intensity were quite similar to that of the present study (group $1 \times 30$ ) and an improvement in glucose tolerance was reported. However, the training programme was of longer duration (6-10 weeks) and newly diagnosed patients were studied [16], in contrast to the present study. Short-term ( $<6$ weeks) exercise programmes in patients with type 2 diabetes mellitus do not always improve glycaemic control [17].
No changes in any of the anthropometrical parameters (BMI, weight, waist circumference and fat mass) were observed in the two exercise groups in the present study. Thus, the improvement of glycaemic control in group $3 \times 10$ was independent of changes in body composition. This is in good agreement with the compatible study by Reitman et al. [16] and is also supported by a meta-analysis [17] including 14 studies of long-term exercise interventions. Thus exercise training can be viewed as beneficial on its own, not merely as an avenue to weight loss. The fact that the body weight did not change in spite of considerable exercise efforts for 4 to 5 weeks in all patients must imply that either the patients increased their daily energy intake or they diminished their habitual physical activity level outside the scheduled training bouts or they did both.

Patients with type 2 diabetes mellitus comprise a very heterogeneous group with highly variable degrees, e.g. of glycaemic control, body weight, co-morbidities and duration of the disease. Accordingly, the response to exercise training with regard to glucose homeostasis will vary considerably [18-20]. It may therefore be important to distinguish between different subgroups of type 2 diabetic patients. The 
fact that no significant effects were seen in group $1 \times 30 \mathrm{~min}$ should therefore not be interpreted strictly and should not discourage patients with type 2 diabetes mellitus from taking exercise. The inclusion criteria for participation in the intervention study enabled us to study the effect of exercise on glycaemic control in a selected target group (middleaged, overweight, male and sedentary). The patients enrolled for the study on their own initiative. Thus, it is not certain that these patients can be considered a representative sample of overweight/obese type 2 diabetic men in the age group 50-70 years. It is likely that the volunteers are a highly selected group on the basis of health consciousness and motivation. Consequently, it is possible that they responded differently to training than other patients with type 2 diabetes mellitus in the selected target group. Obviously, this should be considered before generalising the results to the rest of the population.

A difference in distribution of baseline values between the two exercise groups might distort the effects of training, and in the present study BMI was differently distributed. It cannot be excluded that the difference in BMI between the groups (Table 1) might have influenced the response to training [21]. However, due to the consecutive recruitment of patients, it was not possible to match for BMI. The distribution of BMI was simply the result of the randomised allocation to the exercise intervention groups. Another way to control the distortion would be to adjust for BMI in the analysis. However, with a study sample of no more than 18 persons, the quality of such analysis would be doubtful.

It is well recognised that exercise-induced improvements in glycaemic control diminish when exercise is no longer taken. Training-induced improvements in skeletal muscle insulin sensitivity are lost after 6 to 8 days of de-training [22, 23]. Furthermore, a study of Schneider et al. [19] showed that plasma glucose levels measured twice in the same patient were significantly lower at $12 \mathrm{~h}$ after exercise than at $72 \mathrm{~h}$. We collected all blood samples at least $16 \mathrm{~h}$ after and no later than $72 \mathrm{~h}$ after the last exercise bout (one patient only), but inspection of individual data showed that there was no association between time from last exercise bout and the level of improvement in glycaemic control, indicating that timing of measurements did not affect the results.

Unfortunately, many patients with type 2 diabetes mellitus are physically inactive. Attempts to engage patients in regular training have been disappointing, [24, 25]. The need for methods to incorporate regular exercise as part of the patients' daily activities should be emphasised. The challenge at present must be to translate research findings into practical recommendations with a view to preventing or delaying the long-term complications of diabetes and thereby improving health and quality of life of all individuals with type 2 diabetes mellitus. Involvement and encouragement by the general practitioner is essential [26].
Based on the present results, our recommendation is that multiple sessions $(3 \times 10 \mathrm{~min})$ of aerobic exercise are preferable to one long session $(1 \times 30 \mathrm{~min})$, provided that the goal is improvement of glycaemic control. However, if multiple exercise sessions are virtually impossible, it is worth noting that both exercise regimens have several other positive effects on health, which are independent of glycaemic control.

Acknowledgements We are grateful to all the participating patients for all their efforts. Technical assistance was provided by R. Kraunsøe, J. Bach and T. Bech, M. Sonne and R. Rabøl. Financial support from the Danish Diabetes Association, The Novo Nordisk Foundation, Else and Mogens Wedell-Wedellsborg Foundation, The Augustinus Foundation, Carlsbergs Mindelegat, Adalbert Gade and wife's grant, and Aase and Ejnar Danielsens Foundation is gratefully acknowledged. Duality of interest The authors declare that there is no duality of interest associated with this manuscript.

\section{References}

1. Turner RC, Holman RR, Cull CA et al (1998) Intensive bloodglucose control with sulphonylureas or insulin compared with conventional treatment and risk of complications in patients with type 2 diabetes (UKPDS 33). Lancet 352:837-853

2. Stratton IM, Adler AI, Neil HA et al (2000) Association of glycaemia with macrovascular and microvascular complications of type 2 diabetes (UKPDS 35): prospective observational study. BMJ 321:405-412

3. Port SC, Boyle NG, Hsueh WA, Quinones MJ, Jennrich RI, Goodarzi MO (2006) The predictive role of blood glucose for mortality in subjects with cardiovascular disease. Am J Epidemiol 163:342-351

4. Andersson DK, Svardsudd K (1995) Long-term glycemic control relates to mortality in type II diabetes. Diabetes Care 18:1534-1543

5. Snowling NJ, Hopkins WG (2006) Effects of different modes of exercise training on glucose control and risk factors for complications in type 2 diabetic patients: a meta-analysis. Diabetes Care 29:2518-2527

6. Boule NG, Haddad E, Kenny GP, Wells GA, Sigal RJ (2001) Effects of exercise on glycemic control and body mass in type 2 diabetes mellitus-A meta-analysis of controlled clinical trials. JAMA 286:1218-1227

7. DeBusk RF, Stenestrand U, Sheehan M, Haskell WL (1990) Training effects of long versus short bouts of exercise in healthy subjects. Am J Cardiol 65:1010-1013

8. Baynard T, Franklin RM, Goulopoulou S, Carhart R Jr, Kanaley JA (2005) Effect of a single vs multiple bouts of exercise on glucose control in women with type 2 diabetes. Metabolism 54:989-994

9. Matsuda M, DeFronzo RA (1999) Insulin sensitivity indices obtained from oral glucose tolerance testing: comparison with the euglycemic insulin clamp. Diabetes Care 22:1462-1470

10. Hovorka R, Soons PA, Young MA (1996) ISEC: a program to calculate insulin secretion. Comput Methods Programs Biomed $50: 253-264$

11. Haugaard SB, Andersen O, Volund A et al (2005) Beta-cell dysfunction and low insulin clearance in insulin-resistant human immunodeficiency virus (HIV)-infected patients with lipodystrophy. Clin Endocrinol (Oxf) 62:354-361 
12. Quinn TJ, Vroman NB, Kertzer R (1994) Postexercise oxygen consumption in trained females: effect of exercise duration. Med Sci Sports Exerc 26:908-913

13. Yamanouchi K, Shinozaki T, Chikada K et al (1995) Daily walking combined with diet therapy is a useful means for obese NIDDM patients not only to reduce body weight but also to improve insulin sensitivity. Diabetes Care 18:775-778

14. Braun B, Zimmermann MB, Kretchmer N (1995) Effects of exercise intensity on insulin sensitivity in women with non-insulin-dependent diabetes mellitus. J Appl Physiol 78:300-306

15. Di LC, Fanelli C, Lucidi P et al (2005) Make your diabetic patients walk: long-term impact of different amounts of physical activity on type 2 diabetes. Diabetes Care 28:1295-1302

16. Reitman JS, Vasquez B, Klimes I, Nagulesparan M (1984) Improvement of glucose homeostasis after exercise training in non-insulin-dependent diabetes. Diabetes Care 7:434-441

17. Ligtenberg PC, Hoekstra JB, Bol E, Zonderland ML, Erkelens DW (1997) Effects of physical training on metabolic control in elderly type 2 diabetes mellitus patients. Clin Sci 93:127-135

18. Rogers MA, Yamamoto C, King DS, Hagberg JM, Ehsani AA, Holloszy JO (1988) Improvement in glucose tolerance after $1 \mathrm{wk}$ of exercise in patients with mild NIDDM. Diabetes Care 11:613-618

19. Schneider SH, Amorosa LF, Khachadurian AK, Ruderman NB (1984) Studies on the mechanism of improved glucose control during regular exercise in type 2 (non-insulin-dependent) diabetes. Diabetologia 26:355-360
20. Cuff DJ, Meneilly GS, Martin A, Ignaszewski A, Tildesley HD, Frohlich JJ (2003) Effective exercise modality to reduce insulin resistance in women with type 2 diabetes. Diabetes Care 26:29772982

21. Poirier P, Tremblay A, Broderick T, Catellier C, Tancrede G, Nadeau A (2002) Impact of moderate aerobic exercise training on insulin sensitivity in type 2 diabetic men treated with oral hypoglycemic agents: is insulin sensitivity enhanced only in nonobese subjects? Med Sci Mon 8:CR59-CR65

22. Dela F, Mikines KJ, Larsen JJ, Ploug T, Petersen LN, Galbo H (1995) Insulin stimulated muscle glucose clearance in patients with type 2 diabetes mellitus. Effects of one-legged physical training. Diabetes 44:1010-1020

23. Ruderman NB, Ganda OP, Johansen K (1979) The effect of physical training on glucose tolerance and plasma lipids in maturity-onset diabetes. Diabetes 28(Suppl 1):89-92

24. Skarfors ET, Wegener TA, Lithell H, Selinus I (1987) Physical training as treatment for type 2 (non-insulin-dependent) diabetes in elderly men. A feasibility study over 2 years. Diabetologia 30:930-933

25. Bourn DM, Mann JI, McSkimming BJ, Waldron MA, Wishart JD (1994) Impaired glucose tolerance and NIDDM: does a lifestyle intervention program have an effect? Diabetes Care 17:1311-1319

26. Fritz T, Rosenqvist U (2001) Walking for exercise-immediate effect on blood glucose levels in type 2 diabetes. Scand J Prim Health Care 19:31-33 